УДК 343.131

\title{
Ф.Ф. Зарипов
}

\section{ПРИМЕНЕНИЕ МЕР ОБЕСПЕЧЕНИЯ БЕЗОПАСНОСТИ К УЧАСТНИКАМ УГОЛОВНОГО СУДОПРОИЗВОДСТВА СО СТОРОНЫ ЗАЩИТЫ}

В статье рассматриваются проблемы процессуального регулирования обеспечения безопасности участников уголовного судопроизводства со стороны защиты в процессе производства по уголовному делу. Отмечается, что несмотря на поспешное разделение участников уголовного процесса на группы в соответствии с выполняемой ими процессуальной функцией, необходимость выделения участников уголовного судопроизводства, отстаивающих интересы защиты, в отдельную группу не оспаривается. Обращается внимание на то, что принцип охраны прав и свобод человека и гражданина в уголовном судопроизводстве полностью не регламентирует принятие надлежащих мер по обеспечению безопасности участников уголовного процесса для реализации их прав и интересов. Обосновывается необходимость внесения изменений и дополнений в УПК РФ (в качестве основного источника уголовно-процессуального права), а также в ряд других законодательных актов, имеющих отношение к охране прав и свобод человека и гражданина и к обеспечению безопасности участников уголовного процесса во всех сферах.

Ключевые слова: участники уголовного судопроизводства со стороны защиты, обеспечение безопасности участников уголовного процесса, уголовное судопроизводство, защита человека, его прав и свобод от посягательств на них, практика применения.

DOI: $10.35634 / 2412-9593-2019-29-6-823-829$

Всех участников российского уголовного судопроизводства законодатель разделил, в соответствии с классификацией, основанной на выполняемой ими процессуальной функцией в рамках принципа состязательности сторон. Уголовно-процессуальный закон подразделяет их на 4 группы: а) суд, выполняющий функцию разрешения уголовного дела (ч. 3 ст. 15, ст. 29 УПК РФ); б) участники со стороны обвинения (п. 47 ст. 5, ст. ст. 38-45 УПК РФ); в) участники со стороны защиты (п. 46 ст. 5, ст. ст. 46-55 УПК РФ); г) иные участники уголовного судопроизводства (ст. ст. 56-60 УПК РФ).

На наш взгляд, такая классификация участников уголовного судопроизводства не учитывает смешанный характер российского уголовного процесса, в связи с чем отнесение не только следователя и дознавателя, но и прокурора с потерпевшим к стороне обвинения искажает представление об их процессуальной роли. Например, Ю.К. Якимович видит принципиальные недостатки этой классификации в возвышении принципа состязательности в УПК РФ, в неверном отнесении участников процесса к какой-либо из сторон (защиты либо обвинения), а также в приобщении к участникам процесса эпизодически привлекаемых субъектов ${ }^{1}$. Также актуально мнение И.Я. Фойницкого о том, что «уголовно-судебное разбирательство происходит в общегосударственных интересах, требующих не осуждения обвиняемого во что бы то ни стало, а раскрытия истины, наказание невиновных вредит государству еще более, чем оправдание виновного» ${ }^{2}$. Прав профессор В.А. Азаров в том, что следователь традиционно осуществляет не уголовное преследование, а исследование всех обстоятельств уголовного дела - всесторонне, полно и объективно ${ }^{3}$. Он обязан прежде всего беспристрастно исследовать и раскрыть все обстоятельства по уголовному делу.

К числу участников уголовного судопроизводства со стороны защиты, в соответствии с УПК РФ 2001 г., относятся подозреваемый (ст. 46), обвиняемый (ст. 47), законные представители несовершеннолетнего подозреваемого и обвиняемого (ст. 48), защитник (ст. 49), а также гражданский ответчик (ст. 54) и представитель гражданского ответчика (ст. 55), так как порядок российского уголовного процесса основан на модели соединенного процесса, в котором при разрешении уголовного обвинения допускается рассмотрение гражданского иска. В этом случае мы не оспариваем необходимость

\footnotetext{
${ }^{1}$ Якимович Ю.К. Участники уголовного процесса и субъекты уголовно-процессуальной деятельности // Вестник Омского университета. Сер.: Право. 2008. № 1 (14). С. 110-118.

${ }^{2}$ Фойницкий И.Я. Курс уголовного судопроизводства. СПб., 1996. Т. 1. С. 11.

${ }^{3}$ Азаров В.А., Ревенко Н.И., Кузембаева М.М. Функция предварительного расследования в истории, теории и практике уголовного процесса России. Омск, 2006. С. 129-138.
} 
выделения участников уголовного судопроизводства, отстаивающих интересы защиты, в отдельную группу. Это исходит не только из положения римского права о том, что никто не может быть свидетелем в своем собственном деле - "nullus idoneus testis in re sua intelligitur", , но и из ч. 1 ст. 51 Конституции РФ, которая гласит: «Никто не обязан свидетельствовать против себя самого, своего супруга и близких родственников, круг которых определяется федеральным законом».

В частности, в следственной практике успешно используется якобы законный с точки зрения УПК РФ, но абсолютно противоречащий Конституции РФ способ «обхода» этого постулата - допрос «заподозренного» лица в качестве свидетеля, которое не обладает свидетельским иммунитетом, с целью его перевода в статус подозреваемого признательными показаниями против самого себя 5 . Мы уверены, что лица, вовлекаемые в уголовное судопроизводство в связи с наличием данных о их причастности к совершению преступления, должны наделяться особым статусом, позволяющим им защищаться как лично, так и с помощью профессионального защитника - адвоката.

Специальный закон, регулирующий безопасность участников российского уголовного судопроизводства, а точнее, ст. 2 Федерального закона № 119-Ф3 от 20.08.2004 (в ред. от 07.02.2017) «О государственной защите потерпевших, свидетелей и иных участников уголовного судопроизводства» ${ }^{6}$ к участникам со стороны защиты относит таких лиц, как подозреваемый, обвиняемый, подсудимый, гражданский ответчик, их защитники и законные представители, а также осужденного, оправданного и лицо, в отношении которого уголовное дело либо уголовное преследование прекращено.

Ко всем названным участникам уголовного судопроизводства законодатель допускает возможность применения любых из числа указанных в ст. 6 Федерального закона «О государственной защите потерпевших, свидетелей и иных участников уголовного судопроизводства» № 119-Ф3 (в ред. от 07.02.2017) мер обеспечения их безопасности. В то же время в п. 3 ст. 6 данного Федерального закона указывается на то, что такие меры безопасности, как переселение защищаемого лица на другое место жительства, замена его документов, изменение его места работы, службы или учебы (пп. 4-7 ч. 1 ст. 6 Федерального закона № 119-Ф3) «осуществляются только по уголовным делам о тяжких и особо тяжких преступлениях». Соответственно, с учетом этого законодательного ограничения возможно применение лишь таких мер обеспечения безопасности, как личная охрана, охрана жилища и имущества; выдача специальных средств индивидуальной защиты, связи и оповещения об опасности; обеспечение конфиденциальности сведений о защищаемом лице и временное помещение в безопасное место (пп. 1-3, 8 ст. 6 Федерального закона № 119-Ф3). Указанное законодателем, естественно, не распространяется на подозреваемых и обвиняемых, содержащихся под стражей или находящихся в местах отбывания назначенного судом уголовного наказания. Согласны, что к таким лицам возможно не только применение любой из перечисленных в ст. 6 данного Федерального закона мер обеспечения безопасности, но и других дополнительных мер обеспечения безопасности, включая, например, перевод из одного места содержания под стражей или отбывания наказания в другое (п. 9 ст. 6 указанного Федерального закона).

В качестве мер обеспечения безопасности подозреваемых, обвиняемых и подсудимых выступают и закрепленные в разд. IV УПК РФ меры уголовно-процессуального принуждения, призванные по своему целевому назначению содействовать успешному осуществлению стоящих перед уголовным судопроизводством задач.

По нашему мнению, каждая из мер уголовно-процессуального принуждения характеризуется таким свойством, как содействие в осуществлении выполнения задачи по обеспечению безопасности участников уголовного судопроизводства. Сказанное в полной мере относится к задержанию лица, подозреваемого в совершении преступления (гл. 12 УПК РФ), к любой из мер уголовнопроцессуального пресечения (гл. 13 УПК РФ) вне зависимости от того, требуется ли для их избрания специальное судебное решение (запрет определенных действий, залог, домашний арест, заключение под стражу) или такого решения не требуется (подписка о невыезде и надлежащем поведении, личное

\footnotetext{
${ }^{4}$ Black's Law Dictionary, 9th ed. Bryan A. Garner, ed. St. Paul: West Group, 2009.

5 Подосинникова Л.А. Показания на предварительном следствии свидетеля, ставшего впоследствии обвиняемым. Допустимое ли это доказательство? // Актуальные проблемы российского права. 2007. № 1. С. 588-593.

${ }^{6}$ В силу того что подозреваемые и обвиняемые являются главными (основными) участниками уголовного процесса, их нельзя относить к категории иных участников уголовного судопроизводства, как они названы в Федеральном законе №119-Ф3. Такой закон должен именоваться, например, «О государственной защите потерпевших, свидетелей, подозреваемых, обвиняемых и иных участников уголовного судопроизводства».
} 
Применение мер обеспечения безопасности к участникам уголовного судопроизводства... 825 ЭКОНОМИКА И ПРАВО

2019. Т. 29, вып. 6

поручительство, наблюдение командования воинской части, присмотр за несовершеннолетним подозреваемым или обвиняемым), а также таких мер процессуального принуждения, как отобрание от подозреваемых или обвиняемых обязательства о явке по вызовам, осуществление привода таких лиц, временное отстранение их от должности, наложение ареста на имущество (ч. 1 ст. 111 УПК РФ).

К видам мер обеспечения безопасности участников уголовного судопроизводства, наряду с теми, что закреплены в ст. 5 Федерального закона «О государственной защите судей, должностных лиц правоохранительных и контролирующих органов» № 45-Ф3 (в редакции от 01.07.2017) и в ст. 6 Федерального закона № 119-Ф3 «О государственной защите потерпевших, свидетелей и иных участников уголовного судопроизводства» (в ред. от 07.02.2017), надлежит отнести и следующие из числа применяемых к подозреваемым и обвиняемым в соответствии со ст. 105.1 УПК РФ, запретительные действия: а) выходить в определенные периоды времени за пределы жилого помещения, в котором они проживают в качестве собственника либо на иных законных основаниях; б) находиться в определенных местах, а также ближе установленного расстояния до определенных объектов, посещать определенные мероприятия и участвовать в них; в) общаться с определенными лицами; г) отправлять и получать почтово-телеграфные сообщения; д) использовать средства связи и информационнотелекоммуникационную сеть «Интернет». По мнению исследователей, основные виды латентного противоправного воздействия на участников уголовного процесса, помимо прямо запрещенных Уголовным кодексом РФ способов, применяются в ходе общения, в том числе визуального или телефонного, в виде запугиваний, намеков, которые достигают своей цели и препятствуют должному расследованию и разрешению уголовного дела .

Процессуальный статус подозреваемого как участника уголовного судопроизводства лицо получает при наличии любого из указанного в ч. 1 ст. 46 УПК РФ основания. Как правило, к ним применяется такая мера уголовно-процессуального принуждения, как задержание, сущность которого заключается в немедленном (безотлагательном) взятии подозреваемого под стражу для решения в установленном законом порядке вопроса о возможности его ареста ${ }^{8}$, то есть избрания меры уголовнопроцессуального пресечения - заключение под стражу, с последующим содержанием такого лица, согласно ст. 7 Федерального закона от 15.07.1995 № 103-Ф3 «О содержании под стражей подозреваемых и обвиняемых в совершении преступлений» (в ред. от 19.07.2018 г.): а) в следственных изолятоpax (СИЗО) ФСИН России; б) в изоляторах временного содержания подозреваемых и обвиняемых (ИВС) органов внутренних дел; в) в изоляторах временного содержания подозреваемых и обвиняемых пограничных органов Федеральной службы безопасности; г) в учреждениях уголовноисполнительной системы (УИС); д) на гауптвахтах (для военнослужащих); е) в специально приспособленных для этих целей помещениях на кораблях и зимовках.

После формулирования в отношении подозреваемых в совершении преступления обвинения в постановлении о привлечении в качестве обвиняемого (ст. 176 УПК РФ), обвинительном акте (ст. 225 УПК РФ), обвинительном постановлении (ст. 223.7 УПК РФ) подозреваемый наделяется процессуальным статусом обвиняемого (ч. 1 ст. 47 УПК РФ) и в случае сохранения судом в отношении него прежней меры пресечения переводится для дальнейшего содержания под стражей в следственный изолятор с установленным в них, в соответствии со ст. 15 Федерального закона «О содержании под стражей подозреваемых и обвиняемых в совершении преступлений», режимом содержания и правилами внутреннего распорядка следственных изоляторов (Приказ Минюста России от 14.10.2005 № 189 (в редакции от 31 мая 2018 г.)).

Согласно установленным ст. 7-10 Федерального закона «О содержании под стражей подозреваемых и обвиняемых в совершении преступлений» требованиям, обвиняемые могут содержаться с их согласия в тюрьмах или на территории учреждений, исполняющих назначенное судом уголовное наказание в виде лишения свободы (на территории исправительно-трудовой колонии), либо в специально оборудованных для этих целей помещениях, функционирующих в режиме следственных изоляторов. Необходимость в этом возникает, как правило, в тех случаях, когда обвиняемые могут быть

\footnotetext{
${ }^{7}$ См.: Брусницын Л.В. Применение норм УПК РФ, обеспечивающих безопасность участников уголовного судопроизводства: науч.-практ. пособие. М., 2004. С. 11; Епихин А.Ю., Мишин А.В. Обеспечение безопасности лиц, содействующих уголовному судопроизводству: учеб. пособие. Казань: Изд-во КФУ, 2018. С. 72.

${ }^{8}$ См.: Зинатуллин 3.3. Уголовно-процессуальное принуждения и его эффективность. Казань: Изд-во Казан. унта, 1981. С. 86.; Васильева Е.Г. Меры уголовно-процессуального принуждения. Уфа: Изд-во Башкир. гос. ун-та, 2003. C. 36 .
} 
в досудебном производстве или в суде по уголовным делам о преступлениях, совершенных в соучастии с другими обвиняемыми и (или) подсудимыми либо в составе организованной преступной группы (ОПГ), допрошены в качестве свидетелей ${ }^{9}$, потерпевших, либо их участие необходимо при производстве по выделенному в порядке ст. 154 -155 УПК РФ уголовному делу либо по которому имело место заключение досудебного соглашения о сотрудничестве (гл. 40.1 УПК РФ).

Подозреваемые и обвиняемые как участники уголовного судопроизводства наделены большим объемом процессуальных прав, пользуясь которыми они имеют возможность самым активным образом участвовать в производстве по уголовному делу и тем самым защищать свои субъективные права и законные интересы. Согласно ст. 51 Конституции России, указанные лица имеют «право на молчание», в том отношении, что могут не свидетельствовать против самого себя, своего супруга и близких родственников. Это также, на наш взгляд, является своего рода одним из средств, работающих на обеспечение безопасности подозреваемых и обвиняемых, так как оно предоставляет указанным лицам возможность защититься от необоснованного обвинения, в том числе противоправного воздействия со стороны недобросовестных сотрудников правоохранительных органов.

Серьезным недостатком по отношению к указанной категории участников уголовного процесса является отсутствие в УПК РФ их прямого закрепленного права на обеспечение безопасности. Например, ни в ч. 4 ст. 46 УПК РФ, ни в ч. 4 ст. 47 УПК РФ нет права подозреваемых и обвиняемых ходатайствовать о применении мер безопасности в соответствии с ч. 3 ст. 11 УПК РФ. Хотя это определено, согласно п. 21 ч.2 ст. 42 УПК РФ, в отношении прав потерпевшего и свидетеля (п. 7 ч. 4 ст. 56 ). Думается, что предоставления подозреваемым и обвиняемым права заявлять ходатайства (п. 5 ст. 46 и п. 5 ст. 47 УПК РФ) явно недостаточно. Применение мер обеспечения безопасности в отношении подозреваемых и обвиняемых, а также их близких и родственников необходимо в условиях производства по уголовным делам о преступлениях, совершенных в соучастии и, тем более, в составе организованных преступных групп (ОПГ), в том числе в случаях выделения материалов уголовного дела о групповых преступлениях в отношении лиц, заключивших досудебное соглашение о сотрудничестве со следствием. Представляется, что законодателю в случаях производства по уголовному делу в установленном гл. 40.1 УПК РФ процессуальном порядке надлежало не ограничиваться вынесением следователем постановления о хранении документов в опечатанном конверте в соответствии с ч. 3 ст. 317.4 УПК РФ, а на законодательном уровне закрепить необходимость применения всего комплекса мер обеспечения безопасности указанных выше лиц.

Все сказанное в отношении мер обеспечения безопасности обвиняемых в полной мере проецируется и на подсудимого как участника судебного разбирательства, по обвинению которого в совершении преступления и осуществляется правосудие.

Несмотря на то что только отдельные из предусмотренных в ст. 6 Федерального закона № 119 Ф3 «О государственной защите потерпевших, свидетелей и иных участников уголовного судопроизводства» разновидностей мер безопасности могут применяться для обеспечения государственной защиты подозреваемых и (или) обвиняемых, по нашему мнению, при любых обстоятельствах, связанных с содержанием подозреваемых или обвиняемых под стражей, в соответствии со ст. 13, 68, 73, 84 Уголовно-исполнительного кодекса РФ от 8 января 1997 г. № 1-Ф3 (в ред. от 26.07.2019), администрация соответствующих учреждений обязана предпринимать все меры для обеспечения личной безопасности названных участников уголовного судопроизводства и сохранности их имущества от возможного уничтожения или повреждения ${ }^{10}$.

К сожалению, нормы УПК РФ не регламентируют действия должностных лиц правоприменительных органов по обеспечению безопасности участников уголовного процесса независимо от их процессуального статуса и наличия их ходатайств о защите, так как ходатайство является лишь одним из поводов, но не обязательным условием для применения мер безопасности. В то же время Федеральный закон № 119-Ф3 «О государственной защите потерпевших, свидетелей и иных участников уголовного судопроизводства» называет всех участников уголовного судопроизводства со стороны

\footnotetext{
${ }^{9}$ О негативном отношении к возможности допроса в качестве свидетеля по уголовному делу соучастников преступления, лица, заключившего досудебное соглашение о сотрудничестве см.: Зинатуллин 3.3., Зинатуллин Т.3. Очередные парадоксы уголовно-процессуального регулирования (в связи с Федеральным законом № 72-Ф3 от 18.04.2018 г. и № 376-Ф3 от 30.10.2018) // Судебная власть и уголовный процесс. 2018. № 4. С. 18-22.

${ }^{10}$ Епихин А.Ю., Мишин А.В. Обеспечение безопасности лиц, содействующих уголовному судопроизводству: учеб. пособие. Казань: Изд-во КФУ, 2018. С. 66.
} 
Применение мер обеспечения безопасности к участникам уголовного судопроизводства... 827 ЭКОНОМИКА И ПРАВО

2019. Т. 29, вып. 6

защиты, которые подлежат государственной защите из-за возможных угроз и неправомерного воздействия, но предусматривает применение лишь одной группы мер безопасности: охрану защищаемого лица, временное помещение его в безопасное место и ряд других мер безопасности, что также сужает реализацию прав указанных участников.

Одним из участников уголовного судопроизводства со стороны защиты является защитник, призванный, в соответствии с ч. 1 ст. 49 УПК РФ в установленном уголовно-процессуальным законом порядке осуществлять защиту прав и законных интересов подозреваемых и обвиняемых лиц и оказывать им необходимую юридическую помощь при производстве по уголовному делу. В качестве защитников допускаются адвокаты, являющиеся членами профессионального сообщества адвокатов, которое как институт гражданского общества не входит в систему органов государственной власти и органов местного самоуправления ${ }^{11}$.

После предъявления ордера, выданного соответствующим адвокатским образованием на исполнение поручения в форме оказания подозреваемому, обвиняемому, подсудимому квалифицированной юридической помощи осуществляющему досудебное и (или) судебное производство по уголовному делу соответствующему должностному лицу государства (следователю, судье и т.д.) либо доверенности доверителя из числа любого из указанных выше лиц, адвокат приобретает по конкретному уголовному делу процессуальный статус адвоката-защитника, наделенного всеми закрепленными в статье 53 УПК РФ процессуальными правами и обязанностями ${ }^{12}$.

В нашу задачу не входит исследование всей процессуальной деятельности адвоката-защитника по конкретному уголовному делу (в этом вопросе много проблемных аспектов). Но мы должны обратить внимание на то, что, несмотря на отнесение адвокатов, в соответствии с Федеральным законом № 94-ФЗ от 4 июля 2003 г., к категории лиц, в отношении которых применяется особый порядок производства по уголовным делам (п. 8 ч. 1 ст. 447 УПК РФ), и внесенные Федеральным законом № 73-Ф3 от 17 апреля 2017 г. изменения и дополнения в ч. 2 ст. 29 , чч. $4,4.1$ и 5 ст. 49 , ч. 1 ст. 53 , п. 2.1 ч. 2 ст. 75 УПК РФ, дополнение УПК РФ ст. 450.1, регламентирующей особенности производства обыска, осмотра и выемки в отношении адвоката (надо полагать, речь идет о помещениях, занимаемых адвокатом для выполнения своей работы. - 3.Ф.), и включение адвокатов в перечень подлежащих государственной защите лиц (ст. 2 Федерального закона «О государственной защите потерпевших, свидетелей и иных участников уголовного судопроизводства» от 20 августа 2004 г. № 119-Ф3), безопасность адвокатовзащитников еще должным образом не гарантируется. Законодатель, как нам представляется, не в полной мере учитывает специфику адвокатской деятельности, которая по своему характеру и содержанию, безусловно, относится к категории конфликтных, остропсихологических сфер деятельности ${ }^{13}$. Даже простая беседа с человеком, обвиняемым в совершении преступления, особенно если последнее относится к числу тяжких либо особо тяжких преступлений, способна вызвать не только взрыв эмоций со стороны подозреваемого, обвиняемого, но и совершение с его стороны небезопасных для жизни и здоровья адвоката-защитника, равно как и адвоката-представителя, действий.

Считаем необходимым принятие отдельных норм о государственной защите адвокатов в рамках федеральных законов, в том числе УПК РФ, вне зависимости от того, обладают ли они процессуальным статусом адвоката-защитника или адвоката-представителя. В качестве возможных мер обеспечения безопасности в случае реальных угроз посредством причинения телесных повреждений или иного вреда здоровью, в том числе психологического воздействия, уничтожения или повреждения имущества, в связи с осуществляемой адвокатской деятельностью надлежало бы предусмотреть все меры безопасности, установленные Федеральным законом от 20 августа 2004 г. № 119-ФЗ.

К числу участников уголовного судопроизводства со стороны защиты могут относиться также гражданские ответчики и их представители. Их процессуальный статус регламентируется ст. 54 и 55 УПК РФ. Гражданские ответчики появляются в уголовном процессе в связи с предъявлением к ним со стороны лиц, потерпевших от совершенных в отношении них преступлений (ст. 42 УПК РФ), и гражданских истцов (ст. 44 УПК РФ) исковых требований о возмещении причиненного им матери-

\footnotetext{
${ }^{11}$ См.: Часть 1 ст. 3 Федерального закона «Об адвокатской деятельности и адвокатуре в Российской Федерации» от 31.05.2002 г. № 63-Ф3.

12 Защитник не является должностным лицом государства, а потому он наделяется не полномочиями, как указано в ст. 53 УПК РФ, а процессуальным правами.

${ }^{13}$ Рагулин А.В. Правовые и организационные средства обеспечения реализации профессиональных прав адвоката-защитника в России и пути их совершенствования // Евразийская адвокатура. 2013. 4 (5). С. 62-67.
} 
ального (имущественного), физического или морального вреда. Такое требование законодатель называет «гражданским иском в уголовном процессе». В статусе гражданских ответчиков, как правило, выступают подозреваемые, обвиняемые, подсудимые, а также их представители. В качестве последних при представительстве физического лица выступают обычно адвокаты, а при представительстве юридического лица - лица, привлеченные в соответствии с Гражданским кодексом Российской Федерации представлять их интересы. Отметим, что гражданский ответчик вправе собирать и представлять доказательства, связанные с содержанием исковых требований и обстоятельств, на которых такие требования основаны; снимать за свой счет копии с материалов дела, относящихся к гражданскому иску, в том числе и с использованием технических средств.

Несмотря на то что законодатель не дифференцирует, какие из мер безопасности могут применяться к указанным в Федеральном законе № 119-Ф3 участникам уголовного судопроизводства (он просто ограничивается в ст. 6 их перечислением), к гражданским ответчикам применяются, как правило, следующие меры обеспечения их безопасности: а) личная охрана, охрана жилища и имущества; б) выдача специальных средств индивидуальной защиты, связи и оповещения об опасности; в) обеспечение конфиденциальности сведений о гражданском ответчике и его представителях, чего, естественно, недостаточно. Представляется, что в связи с осуществляемой деятельностью по защите интересов подозреваемого, обвиняемого и подсудимого для таких участников, как законные представители несовершеннолетнего подозреваемого и обвиняемого, гражданского ответчика и представителя гражданского ответчика надлежало бы предусмотреть все меры безопасности, применяемые к основным участникам со стороны защиты и установленные Федеральным законом от 20 августа 2004 г. № 119-Ф3, с соответствующими изменениями в УПК РФ.

К числу мер обеспечения безопасности подозреваемого (обвиняемого) и их представителей надлежит отнести уголовно-процессуальный институт отводов, являющийся гарантией независимого и беспристрастного правосудия, необходимой предпосылкой соблюдения прав и законных интересов участников уголовного судопроизводства. Отводы дают возможность отклонить или устранить из процесса субъекта, объективность которого по тем или иным причинам вызывает сомнения. Процедура отводов обеспечивает осуществление уголовного судопроизводства уполномоченным должностным лицом и является непременным условием законности производимых процессуальных действий и принимаемых процессуальных решений ${ }^{14}$.

Приходится констатировать, что УПК РФ не раскрывает все аспекты по обеспечению безопасности участников уголовного судопроизводства ${ }^{15}$, особенно со стороны защиты, а законодатель не использовал все современные возможности, реализованные международным правом ${ }^{16}$. Для осуществления реальной защиты и применения всех мер обеспечения безопасности, предусмотренных специальными законами в этой сфере, необходимы соответствующие изменения не только в УПК РФ, но и в гражданском, жилищном, трудовом законодательствах относительно указанной проблематики.

Законодательные пробелы, технические и финансовые проблемы существенно осложняют практику применения дорогостоящих мер обеспечения безопасности, в частности, таких, как изменение внешности и замена документов, изменение места работы (службы) или учебы, переселение в другое местожительство для указанной группы участников уголовного судопроизводства несмотря на конституционную обязанность по защите прав и свобод любого участника уголовного процесса.

${ }^{14}$ См.: Федорин В.Е. Процессуальные гарантии объективности следователя // Российский следователь, 2007. № 8; Яковлев Н.А. Институт отвода в демократическом обществе // Экспертиза. 2006. № 12. С. 5; Определение № 1-043/2002 по делу К. // Обзор практики ВС РФ. М., 2003.

${ }^{15}$ См.: Зарипов Ф.Ф. Обеспечение безопасности участников уголовного процесса как самостоятельный принцип российского уголовного судопроизводства // Вестн. Удм. ун-та. Сер. Экономика и право. 2016. Т. 26, вып. 2. C. $92-95$.

${ }^{16}$ См.: Зайцев О., Щерба С. Защита свидетеля в США // Российская юстиция. 1994. № 8; Брусницин Л.В. Меры безопасности для содействующих уголовному правосудию: отечественный, зарубежный и международный опыт // Государство и право. 1998. № 9; Епихин А.Ю. Институт безопасности участников уголовного процесса: сравнительный анализ законодательства зарубежных стран // Актуальные проблемы экономики и права. 2008. № 1; Ширитов А.Б. Возможности интеграции зарубежного опыта в законодательство РФ в сфере защиты свидетелей // Российский следователь. 2007. № 21; Дмитриева А.А. К вопросу об основных направлениях повышения эффективности государственной защиты и безопасности участников уголовного судопроизводства // Вестник Краснодарского ун-та МВД России. 2015. №4 (30); Лозовский Д.Н. Зарубежный опыт обеспечения безопасности участников уголовного судопроизводства. Краснодар: Краснодарский ун-т МВД России, 2016. 
Применение мер обеспечения безопасности к участникам уголовного судопроизводства... 829 ЭКОНОМИКА И ПРАВО 2019. Т. 29, вып. 6

Также важно на основе уже имеющихся процессуальных средств и норм создать четкий и ясный регламент гарантированных действий для правоприменительных органов в каждом случае возникновения угроз и необходимости применения мер государственной защиты.

Поступила в редакцию 22.09.2019

Зарипов Фанис Фаварисович, аспирант

ФГБОУ ВО «Удмуртский государственный университет»

426034, Россия, г. Ижевск, ул. Университетская, 1 (корп. 4)

\section{F.F. Zaripov \\ APPLICATION OF SAFETY MEASURES TO PARTICIPANTS IN CRIMINAL PROCEEDINGS ON THE PART OF THE DEFENCE}

DOI: $10.35634 / 2412-9593-2019-29-6-823-829$

The article formulates the problems of procedural regulation of ensuring the safety of participants in criminal proceedings on the part of the defense in the process of criminal proceedings. It is noted that despite the hasty division of the participants in the criminal process into groups in accordance with the procedural function performed by them, the need to separate the participants in criminal proceedings standing upon the interests of the defense into a separate group is not disputed. Attention is drawn to the fact that the principle of protecting the rights and freedoms of man and citizen in criminal proceedings does not fully regulate the adoption of appropriate measures to ensure the safety of participants in the criminal process for the realization of their rights and interests. The necessity of making amendments and additions to the Code of Criminal Procedure of the Russian Federation (as the main source of criminal procedure law), as well as a number of other legislative acts related to the protection of human and civil rights and freedoms and to ensuring the safety of participants in criminal proceedings in all areas, is substantiated.

Keywords: participants in criminal proceedings on the part of the defense, ensuring the safety of participants in criminal proceedings, criminal proceedings, protecting a person, his rights and freedoms against attacks on them, application practice.

Zaripov F.F., postgraduate student

Udmurt State University

Universitetskaya st., 1/4, Izhevsk, Russia, 426034 